\title{
PENGGUNAAN MEDIA PEMBELAJARAN BERBASIS AUDIO VISUAL UNTUK MATA PELAJARAN KONSTRUKSI BANGUNAN
}

\author{
Anggi Aris Rinaldi', Daryati', Riyan Arthur ${ }^{3}$ \\ ${ }^{1}$ Alumni PTB FT UNJ, anggiarisrinaldi.nr12@gmail.com \\ 2Dosen PTB FT UNJ, daryati sr@uni.ac.id \\ 3Dosen PTB FT UNJ, arthur@unj.ac.id
}

\begin{abstract}
Abstrak
Penelitian ini bertujuan untuk mengetahui peran media pembelajaran berbasis audio visual dalam meningkatkan hasil belajar siswa pada mata pelajaran konstruksi bangunan pada siswa kelas X TGB di SMK Negeri 56 Jakarta. Penelitian berlangsung dari November 2016 sampai dengan Januari 2017.

Metode yang digunakan dalam penelitian ini adalah metode eksperimen dengan bentuk penelitian nonequivalent control group design, yaitu penelitian yang dilakukan dalam satu populasi yang telah dibagi menjadi 2 kelompok. Kelompok kelas eksperimen diberikan perlakuan media audio visual sedangkan untuk kelas kontrol diberi perlakuan media konvensional, selain itu media pembelajaran yang dibuat divalidasi terlebih dahulu oleh beberapa ahli untuk mendapatkan kelayakan uji coba. Selanjutnya uji coba dilakukan pada peserta didik kelas X bidang keahlian Teknik Gambar Bangunan di SMK Negeri 56 Jakarta yang berjumlah 56 siswa. Analisis data menggunakan uji-t dua pihak sample independen melalui program aplikasi SPSS 23.

Hasil penelitian ini adalah: Berdasarkan nilai hasil belajar yang diperoleh, pada kelas eksperimen rata-rata nilai pre-test sebesar 55,79 dan terjadi peningkatan yang signifikan di hasil post-test dimana pada kelas eskperimen mendapatkan nilai rata-rata sebesar 89,54. Sedangkan untuk kelas kontrol rata-rata nilai pre-test yang diperoleh sebesar 62,39 dan pada saat post-test memperoleh nilai rata-rata sebesar 82,61. Kelas eksperimen memperoleh selisih rerata hasil belajar (pre-test \& post-test) ilmu bahan bangunan sebesar 33,75 dan peningkatan yang terjadi sekitar 16,88\%. Sedangkan pada kelas kontrol, selisih rerata hasil belajar (pre-test \& post-test) ilmu bahan bangunan sebesar 20,22 dan peningkatan yang terjadi sebesar 10,11\%. Maka hal tersebut mengindikasikan bahwa penggunaan media audio visual turut berperan dalam peningkatan hasil belajar siswa pada kelas eksperimen. Maka dapat disimpulkan bahwa terdapat pengaruh positif terhadap penggunaan media audio visual dalam meningkatkan hasil belajar dalam mata pelajaran konstruksi bangunan pada siswa kelas X TGB di SMK Negeri 56 Jakarta.
\end{abstract}

Kata kunci: Media Pembelajaran, Media Berbasis Audio Visual, Konstruksi Bangunan 


\title{
USE OF AUDIO-VISUAL MEDIA BASED LEARNING FOR BUILDING CONSTRUCTION SUBJECTS
}

\author{
Anggi Aris Rinaldi ${ }^{1}$, Daryati ${ }^{2}$, Riyan Arthur ${ }^{3}$ \\ ${ }^{1}$ Alumni of PTB FT UNJ, anggiarisrinaldi.nr12@gmail.com \\ ${ }^{2}$ Lecturer of PTB FT UNJ, daryati sn@,unj.ac.id \\ ${ }^{3}$ Lecturer of PTB FT UNJ, arthur@unj.ac.id
}

\begin{abstract}
This study aim to determine the role of audio visual media based learning to improve student learning outcomes in building construction subjects in class X TGB in SMK Negeri 56 Jakarta. Research lasted from November 2016 until January 2017.

This research using experimental methods to form nonequivalent control group design study, the research carried out in a population that has been divided into two groups. Group 1 called experiment class will be treatment by the audio visual media and group 2 called control class will be treatment by the conventional media, in addition to the media that were made are validated in advance by some expert to get feasibility trial. Further trials conducted on student of class X TGB at SMK Negeri 56 Jakarta totaling 56 student. The data analysis using t-test two parties independent sample through an application program SPSS 23.

The result of this research are: Based on the study result obtained, the experiment class average pre-test score of 55,79 and get a significant increase in post-test result in which class experiment get the average value of 89,54. And for the control class average pre-test score of 62,39 and get a increase in the post-test average value of 82,61. the experiment class gained a mean difference of learning outcomes (pre-test and post-test) the building material subject amounted to 33,75 and the improvement that occured around 16,88\%. While in the control class the mean difference in learning outcomes (pre-test and post-test) the building material subject amounted to 20,22 and the improvement that occured at 10,11\%. Then it indicates that the use of audio visual media play role in improving student learning outcomes in the experiment class. It can be concluded that there is a positive effect on the use of audio visual media in improving learning outcomes in bulding construction subject in class $X$ TGB SMK Negeri 56 Jakarta.
\end{abstract}

Keywords: Media Learning, Audio Visual Media Based Learning, Building Construction Subjects

\section{Pendahuluan}

\section{Latar Belakang}

Perkembangan teknologi pendidikan tidak dapat dilepaskan dengan perkembangan teknologi pada umumnya. Berbagai perangkat pendidikan dan sarana pendidikan yang modern turut mendukung optimalisasi proses pembelajaran, baik di tingkat sekolah maupun dalam kehidupan sehari-hari.
Perkembangan teknologi khususnya teknologi informasi dan komunikasi banyak menawarkan berbagai kemudahankemudahan dalam pembelajaran, yang memungkinkan terjadinya pergeseran orientasi pembelajaran dari proses penyajian berbagai pengetahuan menjadi proses bimbingan dalam melakukan eksplorasi individual terhadap ilmu pengetahuan. Di samping itu juga sangat dimungkinkan perubahan paradigma dari filosofi pembelajaran berpusat kepada guru (teachers 
centered) menjadi pembelajaran berpusat kepada siswa (student centered).

Dalam proses pembelajaran, pengembangan materi atau bahan ajar dapat melalui berbagai cara, salah satunya adalah pengembangan bahan ajar dengan optimalisasi media. Media yang digunakan untuk memperlancar komunikasi dalam proses pembelajaran sering diistilahkan media pembelajaran. Salah satu media yang digunakan dalam pembelajaran dan diyakini dapat lebih menggairahkan animo siswa dalam proses pembelajaran di kelas adalah media Audio Visual.

Media audio visual merupakan salah satu saran alternatif dalam mengoptimalkan proses pembelajaran, dikarenakan beberapa aspek antara lain mudah dikemas dalam proses pembelajaran, lebih menarik untuk pembelajaran, dan dapat diedit setiap saat.

Terkait dengan media pembelajaran yang akan digunakan dengan materi yang akan diajarkan guru, salah satu mata pelajaran di SMK untuk program keahlian gambar bangunan adalah Konstruksi Bangunan yang merupakan mata pelajaran kejuruan yang wajib diajarkan kepada siswa. Mata pelajaran Konstruksi Bangunan berisi tentang bagaimana mendata, mendesain, melaksanakan dan memelihara suatu bangunan. Intinya adalah mencari tahu bagaimana cara membangun dengan mudah, kuat, murah, kualitas bagus dan tahan lama.

Hasil observasi pendahuluan yang dilakukan penulis di SMKN 56 Jakarta pada bulan Agustus 2016 menunjukkan bahwa nilai hasil belajar pada kelas X TGB tahun ajaran 2016/2017 pada sub materi batu bata menunjukan dari 56 siswa terdapat 42 siswa yang telah memenuhi kriteria ketuntasan minimal (KKM), sedangkan 14 siswa lainnya belum memenuhi KKM. Bagi guru mata pelajaran hal ini dirasa kurang memuaskan mengingat guru menginginkan seluruh siswa memenuhi KKM yang di tetapkan. Kriteria Ketuntasan Minimum (KKM) yang ditetapkan disekolah adalah 75.
Selama ini pembelajaran mata pelajaran ilmu konstruksi bangunan menggunakan media pembelajaran yang sederhana yang membuat siswa menjadi kurang termotivasi dan merasakan kejenuhan ketika proses pembelajaran dilakukan. Untuk itu perlu adanya perubahan di dalam penggunaan media guna meningkatkan hasil belajar.

Salah satu materi mata pelajaran konstruksi bangunan adalah batu bata, pengoptimalan media audio visual untuk materi pelajaran batu bata tentu selain meningkatkan animo siswa ketika proses pembelajaran di kelas juga diyakini akan meningkatkan hasil belajar siswa terhadap materi pelajaran batu bata ini. Pada mata pelajaran konstruksi bangunan di SMK negeri 56 Jakarta kompetensi dasar yang digunakan untuk 2 semester adalah $12 \mathrm{KD}$, tetapi peneliti hanya mengambil $1 \mathrm{KD}$ mengenai batu bata. Penentuan KD yang akan di teliti berdasarkan hasil observasi pendahuluan yang dilakukan.

Berdasarkan uraian di atas, maka penulis tertarik untuk melakukan penelitian yang berjudul: "Penggunaan Media Pembelajaran Berbasis Audio Visual Untuk Mata Pelajaran Konstruksi Bangunan”.

\section{Tujuan Penelitian}

Adapun tujuan dari penelitian ini adalah:

1. Untuk mengetahui pengaruh media pembelajaran berbasis audio visual terhadap hasil belajar siswa kelas $\mathrm{X}$ TGB 1 dan 2 SMK negeri 56 Jakarta materi Batu Bata.

2. Media pembelajaran berbasis audio visual dapat membantu peserta didik dalam memahami materi pembelajaran batu bata dalam mata pelajaran konstruksi bangunan.

\section{Manfaat Penelitian}

Manfaat penelitian ini dapat dibedakan menjadi dua yaitu Manfaat secara teoritis dan Manfaat praktis: 
a. Manfaat Teoretis

Manfaat teoretis dalam penelitian ini yaitu sebagai suatu karya ilmiah, hasil dari penelitian ini nantinya diharapkan bisa memberikan kontribusi pada pendidik, peserta didik dan masyarakat pada umumnya serta diharapkan bisa memberikan konstribusi yang baik pula bagi perkembangan ilmu pengetahuan khususnya mengenai penggunaan media audio visual dalam mata pelajaran konstruksi bangunan kelas X Teknik Gambar Bangunan SMK Negeri 56 Jakarta.

b. Manfaat Praktis

Manfaat praktis yang dapat diambil dari penelitian ini, yaitu:

1. Dapat mempermudah pemahaman siswa mengenai materi mata pelajaran konstruksi bangunan.

2. Dapat membantu siswa untuk memvisualisasikan hal-hal yang sekiranya masih abstrak dalam materi mata pelajaran ilmu bahan bangunan.

3. Sebagai pelengkap media presentasi pembelajaran konstruksi bangunan.

4. Diharapkan dapat digunakan sebagai acuan pengembangan media audio visual dalam mata pelajaran ilmu bahan bangunan guna meminimalisir kejenuhan dan kebosanan serta menjauhkan kesan monoton dalam proses pembelajaran konvensional di dalam kelas yang mengakibatkan motivasi belajar siswa menjadi berkurang untuk memahami materi yang disajikan oleh guru.

\section{Pembatasan Masalah}

Berdasarkan identifikasi masalah, didapati masalah yang ada sangatlah luas dan beragam sehingga agar penelitian lebih terfokus dan tidak meluas dari pembahasan yang dimaksud, peneliti membatasinya pada ruang lingkup penelitian yaitu:

1. Penggunaan media pembelajaran berbasis audio visual untuk mata pelajaran konstruksi bangunan pada materi batu bata di SMKN 56 Jakarta.
2. Instrumen penilaian berupa soal pilihan ganda dengan materi soal batu bata.

3. Instrumen penilaian hanya mengukur kemampuan ranah kognitif siswa pada materi batu bata.

4. KD yang akan dibahas dalam penelitian ini berkaitan dengan materi Batu Bata.

\section{Metode Penelitian}

Penelitian ini termasuk jenis penelitian dan pengembangan (Research and Development). Menurut Sugiyono (2011) "penelitian dan pengembangan adalah metode penelitian yang digunakan untuk menghasilkan produk tertentu, dan menguji keefektifan produk tersebut".

Metode yang digunakan dalam penelitian ini adalah metode eksperimen. Pada metode ini, pengajar memberikan perlakuan pembelajaran secara langsung kepada sampel penelitian yaitu dengan memberikan pembelajaran menggunakan media audio visual pada kelas eksperimen dan pembelajaran tanpa menggunakan media audio visual (konvensional) pada kelas kontrol.

Tabel 1. Desain Eksperimen

\begin{tabular}{lccc}
\hline Kelompok & Pre-test & Perilaku & Post-test \\
\hline Eksperimen & $\mathrm{Y}_{1}$ & $\mathrm{X}_{1}$ & $\mathrm{Y}_{2}$ \\
\hline Kontrol & $\mathrm{Y}_{1}$ & $\mathrm{X}_{2}$ & $\mathrm{Y}_{2}$
\end{tabular}

\section{Keterangan:}

Eksperimen : Kelompok Kelas

Eksperimen (kelas yang menggunakan media audio visual)

Kontrol : Kelompok kelas Kontrol (kelas yang menggunakan media konvensional)

$\mathrm{X}_{1} \quad$ : Pembelajaran dengan media audio visual

$\mathrm{X}_{2} \quad$ : Pembelajaran dengan media konvensional

$\mathrm{Y}_{1} \quad$ : Nilai pre-test

$\mathrm{Y}_{2} \quad$ : Nilai post-test

\section{Pembahasan Penelitian}

Tujuan penelitian ini adalah untuk mengetahui peran media audio visual dalam 
meningkatkan hasil belajar siswa pada mata pelajaran konstruksi bangunan. Subjek penelitian ini berjumlah 56 siswa yang dibagi menjadi dua kelompok yaitu kelompok kelas eskperimen (28 siswa) dan kelompok kelas kontrol (28 siswa). Sebelum melakukan uji coba lapangan terlebih dulu peneliti melakukan evaluasi terhadap beberapa ahli untuk mengetahui kelayakan media yang akan diujicobakan. Pada tahap evaluasi dilakukan penilaian media yang dibuat oleh beberapa ahli diantaranya 2 orang ahli materi yaitu Ibu Dr. Gina Bachtiar, MT (Dosen Jurusan Teknik Sipil UNJ) dan Bapak Drs. Sudarmanto (Guru SMK Negeri 56 Jakarta) serta 1 orang ahli media yaitu Bapak Cecep Kustandi, M.pd (Dosen Teknologi Pendidikan UNJ). Penilaian dari ahli tersebut bertujuan untuk mengetahui kelayakan media yang telah dibuat, penilaian oleh para ahli diperoleh sebagai berikut: (1) Validasi oleh ahli materi 1 menyatakan baik dengan presentase $71 \%$; (2) Validasi oleh ahli materi II menyatakan baik dengan presentase 78\%; (3) Validasi oleh ahli media menyatakan sangat baik dengan presentase $86 \%$. Sehingga dapat disimpulkan bahwa media audio visual ilmu bahan bangunan dari segi materi dan media layak dan baik untuk digunakan dalam proses pembelajaran.

Setelah dilakukan penilaian kualitas media, selanjutnya dilakukan uji coba lapangan. Adapun sekolah yang menjadi tempat penelitian peneliti adalah SMK Negeri 56 Jakarta, uji coba dilakukan pada kelas X (TGB 1\&2). Peserta didik pada kelas eksperimen yang menggunakan media berbasis audio visual dengan metode ceramah dan penugasan lebih memberikan respon positif berupa keaktifan bertanya, dan lebih aktif dalam menjawab evaluasi soal pada media. Hal ini tidak diikuti peserta didik pada kelas kontrol yeng menggunakan media power point dengan metode ceramah, yakni cenderung kurang memperhatikan penjelasan pada media

Setelah dilakukan uji coba, selanjutnya dilakukan pengukuran pada hasil belajar peserta didik melalui tes pilihan ganda sebanyak 15 soal. Kompetensi dasar yang diuji pada tes adalah KD 3.2 Menerapkan spesifikasi dan karakteristik batu bata, beton, keramik, dan genting untuk konstruksi bangunan dan KD 4.2 mengelola spesifikasi dan karakteristik batu bata, beton, keramik, dan genting untuk konstruksi bangunan. Berdasarkan nilai hasil belajar yang diperoleh, maka kelas eksperimen memperoleh selisih rerata hasil belajar (pre-test \& post-test) konstruksi bangunan sebesar 33,75 dan peningkatan yang terjadi sekitar 16,88\%. Sedangkan pada kelas kontrol, selisih rerata hasil belajar (pretest \& post-test) konstruksi bangunan sebesar 20,22 dan peningkatan yang terjadi sebesar 10,11\%. Maka dapat disimpulkan bahwa rerata hasil belajar konstruksi bangunan kelas eksperimen mengalami peningkatan lebih baik dibandingkan dengan kelas kontrol. Hal tersebut sesuai dengan manfaat media oleh, Dale dalam Azhar Arsyad (2010) dikatakan bahwa: (1) Media pembelajaran dapat memperjelas pesan dan informasi sehingga mamperlancar dan meningkatkan proses belajar dan hasil belajar; (2) Meningkatkan dan mengarahkan perhatian anak sehingga menimbulkan motivasi belajar; (3) Mengatasi keterbatasan indera, ruang dan waktu, (4) Memberikan kesamaan pengalaman dan memungkinkan terjadinya interaksi langsung (Arsyad, 2014).

Hasil kajian ini juga ditunjang oleh penelitian dari Sapto Haryoko (2009), Efektifitas Pemanfaatan Media Audio Visual Sebagai Alternatif Optimalisasi Model Pembelajaran. Desain penelitian yang diterapkan dalam penelitian ini adalah the pre-test - post-test - control group design. Hasil penelitian menunjukan bahwa kelas teknik jaringan komputer yang diajarkan menggunakan media audio visual lebih tinggi skornya jika dibandingkan dengan kelas kontrol (kelas teknik jaringan komputer dengan media konvensional). Perbedaan penelitian Sapto haryoko dengan penelitian ini diantaranya jenis mata pelajaran yang diteliti berbeda dan objek penelitian nya pun berbeda, desain penelitian yang digunakan dalam penelitian 
ini hanya menggunakan pre-test - post-test design. Namun hasil penelitian antara penelitian Sapto haryoko dengan penelitian ini secara garis besar sama.

Widha Nur Agastya (2009), Pengembangan Media Audio Visual Materi Pokok Senyawa Hidrokarbon Bagi Siswa SMA Kelas X Semester 2 Berdasarkan Standar Isi. Penilaian pengembangan media audio visual dilakukan oleh 6 guru kimia SMA/MA. Instrument penilaian berupa data kualitatif kemudian ditabulasi menjadi data kuantitatif. Hasil penelitian menunjukan media audio visual yang dikembangkan mempunyai kualitas yang baik (B) menurut penilaian 6 orang guru kimia dengan skor 95,83 dari skor maksimal 120 dan presentase keidealan 79,83\%. Dengan demikian layak digunakan sebagai alat bantu media pembelajaran audio visual. Perbedaan penelitian Widha dengan penelitian ini terdapat pada jenis media yang dikembangkan, Widha mengembangkan media untuk mata pelajaran kimia sedangkan media yang dikembangkan dalam penelitian ini untuk mata pelajaran ilmu bahan bangunan, penelitian yang dilakukan oleh Widha secara garis besar dilakukan hanya untuk mengetahui kelayakan medianya saja dan tidak di uji cobakan kepada siswa. Sedangkan penelitian ini selain mengetahui kelayakan media yang dibuat dan divalidasi oleh beberapa ahli, juga di uji cobakan kepada siswa.

Muhammad Adib Kurniawan (2013), Penggunaan Media Presentasi Pembelajaran Berbasis Visualisasi Tiga Dimensi Terhadap Hasil Belajar Siswa Pada Mata Pelajaran Konstruksi Bangunan Gedung. Metode penelitian yang digunakan adalah penelitian eksperimen dimana subjek pada penelitian ini adalah siswa kelas XI TGB 1 (kelas ekperimen) dan kelas XI TGB 2 (kelas kontrol). Berdasarkan hasil penelitian diambil kesimpulan bahwa pembelajaran dengan menggunakan media presentasi pembelajaran berbasis visualisasi tiga dimensi dapat meningkatkan hasil belajar siswa serta dapat meningkatkan presentase ketuntasan belajar. Pada penelitian Adib media yang digunakan adalah media presentasi yang menggunakan konten animasi (audio visual) berbeda dengan media yang dibuat dalam penelitian ini berupa video animasi. Desain penelitian yang digunakan adalah eksperimen dimana terdapat kelas eksperimen dan kontrol.

\section{Keterbatasan Penelitian}

Walaupun penelitian ini telah dilakukan secara optimal untuk mengetahui hasil pencapaian akhir penelitian yang diharapkan, namun demikian penulis menyadari dalam penelitian ini ada suatu keterbatasan yang sulit dihindari, adapun keterbatasan dari penelitian ini antara lain:

1. Penelitian ini hanya mengambil 1 dari 12 $\mathrm{KD}$ saja, sehingga dibutuhkan penelitian berkelanjutan untuk dapat benar-benar mengetahui dampak penggunaan media pembelajaran berbasis audio visual yang akan diteliti.

2. Pada saat melakukan validasi terhadap ahli media maupun materi peneliti tidak mengsinkronisasikan media yang di validasi dengan soal evaluasinya sehingga antara media dan soal evaluasinya kurang sinkron.

3. Diperlukan kemampuan tambahan bagi guru untuk menyampaikan materi dengan media audio visual ini sehingga tujuan pembelajaran dapat tercapai.

\section{Kesimpulan}

Hasil dari penelitian ini menunjukan bahwa penggunaan media pembelajaran berbasis audio visual pada mata pelajaran konstruksi bangunan sub materi batu bata memberikan pengaruh terhadap hasil belajar. Hal ini dibuktikan pada proses pembelajaran di kelas. Hal tersebut didukung dengan perolehan selisih rerata hasil belajar (pre-test \& post-test) pada kelas eksperimen sebesar 33,75 dan peningkatan yang terjadi sekitar $16,88 \%$. Sedangkan pada kelas kontrol, selisih rerata hasil belajar (pretest \& post-test) sebesar 20,22 dan peningkatan yang terjadi sekitar 10,11\%. Hal tersebut mengindikasikan bahwa 
penggunaan media audio visual turut berperan dalam peningkatan hasil belajar siswa pada kelas eksperimen. Maka dapat disimpulkan bahwa terdapat pengaruh penggunaan media audio visual kompetensi dasar batu bata untuk mata pelajaran konstruksi bangunan terhadap hasil belajar pada siswa kelas X TGB SMKN 56 Jakarta.

\section{Implikasi}

Berdasarkan hasil penelitian maka tindak lanjut yang dapat diberikan diantaranya:

1. Media pembelajaran berbasis audio visual yang dibuat akan lebih optimal jika guru sebagai pendidik meningkatkan inovasi yang terbaru sehingga kegiatan pembelajaran menjadi bervariasi.

2. Media pembelajaran berbasis audio visual ini akan lebih bermanfaat jika digunakan oleh peserta didik dengan dibimbing oleh guru mata pelajaran yang bersangkutan, sehingga akan dapat mempermudah dalam memahami materi dan meningkatkan hasil belajar peserta didik.

3. Pengembangan media audio visual ini membutuhkan keterampilan serta waktu yang lebih, agar media yang dihasilkan sesuai dengan kebutuhan peserta didik. Pada proses pelaksanaannya media audio visual ini akan lebih optimal digunakan jika sarana komputer di sekolah dapat digunakan pada mata pelajaran ilmu bahan bangunan, agar peserta didik dapat mengakses media secara individu.

\section{Saran}

Berdasarkan hasil penelitian ini maka peneliti mengajukan beberapa saran diantaranya:

1. Guru juga perlu diberikan pelatihan pembuatan media pembelajaran berbasis teknologi agar memperluas wawasan.

2. Guru harus sering-sering meng-update pengetahuan tentang pengembangan media pembelajaran.

3. Guru perlu mempelajari kebutuhan media pembelajaran pada setiap mata pelajaran yang diampu.

4. Guru harus bisa untuk memanfaatkan teknologi terkini guna mengembangkan media pembelajaran.

\section{Daftar Pustaka}

Arsyad, A. 2014. Media Pembelajaran Ed.rev. Jakarta: Rajawali Pers.

Azhar, Arsyad. (2010). Media Pembelajaran. Jakarta: PT. Raja Grafindo Persada

Muhammad Adib kurniawan. (2013). Penggunaan Media Presentasi Pembelajaran

Berbasis Visualisasi Tiga Dimensi Terbadap Hasil Belajar Siswa Pada Mata Pelajaran Konstruksi Bangunan Gedung. Skripsi. Semarang: Universitas Negeri Semarang

Sapto Haryoko. (2009). Efektifitas Pemanfaatan Media Audio Visual Sebagai Alternatif Optimalisasi Model Pembelajaran. Makassar: Universitas Negeri Makassar.

Sugiyono. 2011. Metode Penelitian Pendidikan Kuantitatif, Kualitatif, dan RळD. Bandung: Alfabeta.

Widha Nur Agastya. (2009). Pengembangan Media Audio Visual Materi Pokok Senyawa Hidrokarbon Bagi Siswa SMA/MA Kelas $X$ Semester 2 Berdasarkan Standar Isi. Skripsi. Yogyakarta: Universitas Islam Negeri Sunan Kalijaga. 